\title{
Paediatric continuing medical education needs and preferences of UNRWA physicians in Jordan
}

\author{
A. Nasir, ${ }^{7}$ A. Khader, ${ }^{2}$ L. Nasir, ${ }^{3}$ I. Abuzayed ${ }^{4}$ and A. Seita ${ }^{2}$
}

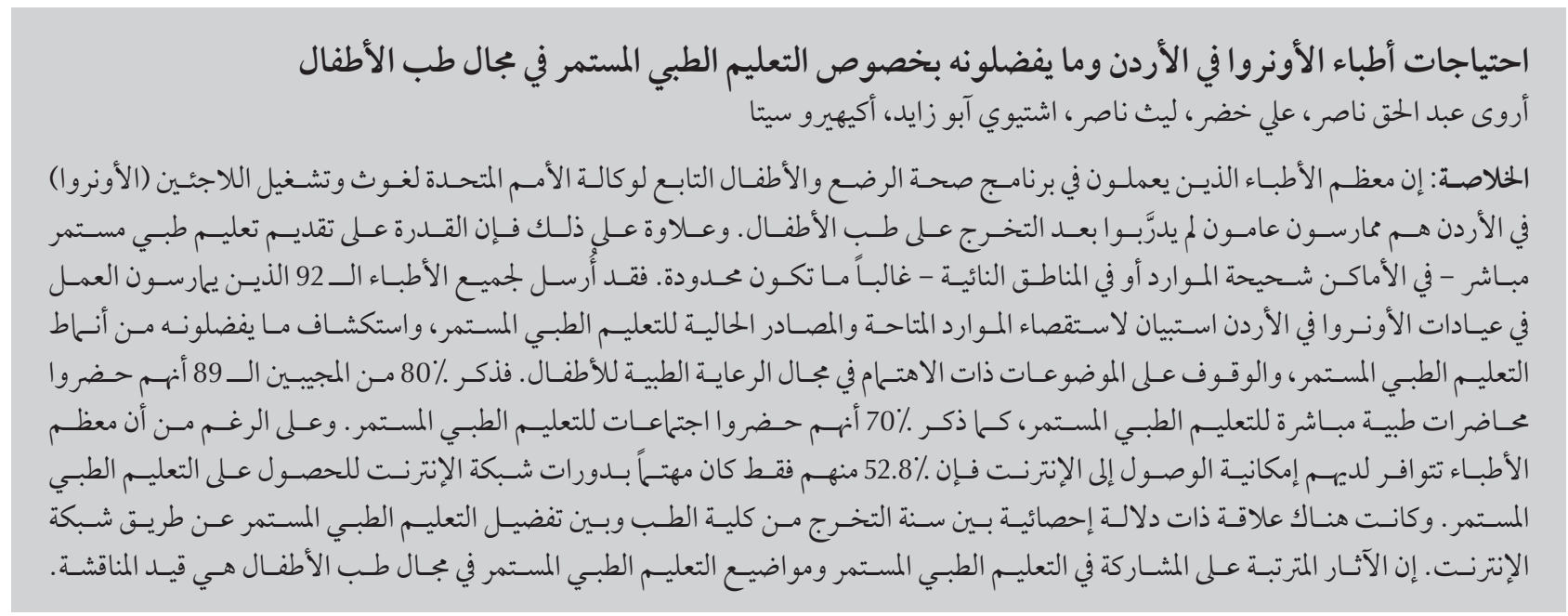

ABSTRACT Most physicians who work in the United Nations Relief and Works Agency (UNRWA) infant and child health programme in Jordan are general practitioners with no postgraduate training in paediatrics. Furthermore, in resource-poor or remote settings, the ability to deliver live continuing medical education (CME) is often limited. A questionnaire exploring the resources available for accessing $\mathrm{CME}$, preferences for types of CME, current sources of CME and topics of interest in the field of paediatric care was sent to all 92 physicians practising in UNRWA clinics in Jordan. Of the 89 respondents $80 \%$ had attended live medical lectures for CME and 70\% CME meetings. Despite most physicians having access to the Internet only 52.8\% were interested in Internet-based courses for accessing CME. There was a statistically significant relationship between year of graduation from medical school and preference for Internet-based CME. Implications for CME participation and paediatric CME topics are discussed.

Besoins et préférences en matière de formation médicale continue en pédiatrie des médecins exerçant en Jordanie de l'Office de secours et de travaux des Nations Unies pour les réfugiés de Palestine dans le Proche-Orient

RÉSUMÉ La plupart des médecins qui travaillent pour le programme de santé du nourisson et de l'enfant en Jordanie à l'Office de secours et de travaux des Nations Unis pour les réfugiés de Palestine dans le Proche-Orient (UNRWA) sont des médecins généralistes sans spécialisation en pédiatrie. Par ailleurs, dans un contexte de ressources limitées ou dans des zones isolées, la capacité à dispenser une formation médicale continue (FMC) est souvent limitée. Un questionnaire étudiant les ressources disponibles qui permettent d'accéder à la formation médicale continue, les types de formation préférés, les sources actuelles de formation médicale continue et les sujets d'intérêt dans le domaine des soins pédiatriques a été envoyé à l'ensemble des 92 médecins exerçant dans des cliniques de l'UNRWA en Jordanie. Sur un total de 89 répondants, 80 \% avaient assisté en personne à des conférences médicales dans le cadre de la formation médicale continue et $70 \%$ à des réunions de formation médicale continue. Si la plupart des médecins avaient accès à I'Internet, seuls 52,8 \% étaient intéressés par des cours en ligne permettant d'accéder à la formation médicale continue. Il existait une relation statistiquement significative entre l'année de fin d'études en faculté de médecine et la préférence pour une formation médicale continue sur l'Internet. Les implications pour une participation à la formation médicale continue et les sujets de formation médicale continue en pédiatrie sont en cours de discussion.

${ }^{'}$ Section of General Paediatrics, Department of Paediatrics, University of Nebraska Medical Center, Omaha, Nebraska, United States of America (Correspondence to A. Nasir: anasir@unmc.edu). ${ }^{2}$ Department of Health, UNRWA Headquarters, Amman, Jordan. ${ }^{3}$ Department of Family Medicine, Creighton University School of Medicine, Omaha, Nebraska, United States of America. ${ }^{4}$ Department of Health, UNRWA Jordan Field Office, Amman, Jordan.

Received: 29/09/14; accepted: 29/10/15 


\section{Introduction}

Continuing medical education (CME) allows physicians to keep up with advances in medical knowledge that affect patient care. Evidence indicates that $\mathrm{CME}$ can be effective in improving knowledge, attitudes, skills and behaviours (1). While Internet-based learning has been found to be associated with large positive effects on knowledge compared with no intervention, a meta-analysis of 81 trials has suggested that CME interventions that result in measureable improvements in patient outcomes are those that provide a combination of didactic and interactive elements (2).

The health programme of the United Nations Relief and Works Agency for Palestine Refugees in the Near East (UNRWA) delivers primary health care services to over 3 million Palestinian refugees in the Gaza Strip, the West Bank, Jordan, Syrian Arab Republic and Lebanon (3). Through their infant and child health programme, UNRWA provides care for children across all phases of the life cycle, with specific interventions that meet the health needs of newborns, infants and school-age children. Both preventive and curative care is provided, with a special emphasis on prevention. In Jordan, UNRWA clinics are located in both refugee camps and in the community, at various locations throughout the country (Table 1).

Physicians working in resourcelimited countries or remote areas often have limited access to CME venues. This has an impact on their ability to access advances in medical knowledge and skills. Internet-based CME activities offer a potential solution to this problem (4). Particularly in resourcepoor or remote settings, the ability to deliver live CME is often limited. This makes Internet-based delivery of courses and information a potentially attractive method by which information and education might be disseminated.
Most physicians who work in the UNRWA infant and child health programme are general practitioners with no postgraduate training in paediatrics. CME on paediatric topics has been identified by both physicians and the UNRWA leadership as being very important in maintaining and improving the quality and efficiency of health care in the UNRWA clinics in Jordan. Since little is known about the CME needs of UNRWA physicians, we wanted to explore their current practices and format preferences for $\mathrm{CME}$, with an emphasis on paediatric topics.

\section{Methods}

A questionnaire was developed for this survey by a team comprised of a board-certified academic paediatrician, a board-certified academic family physician and physician leaders in the UNRWA health department headquarters in Amman, Jordan. The questionnaire was also reviewed by the Center for Continuing Education at the University of Nebraska medical centre in Omaha, United States of America. It explored preferences, practices and access to CME as well as content needs in paediatrics. The questionnaire was reviewed and approved by the ethics committee at the UNRWA headquarters.
The paper questionnaire was sent in February 2014 to the UNRWA physicians who staff the 23 primary health care centres in the 6 regions in Jordan. The questions explored the following themes: the preferred format for CME; current sources of CME; resources available to allow participation in online and other types of CME; and preferred paediatric topics for CME

Counts and percentages were used to describe all variables. Fisher exact test was used to determine associations between questions. A $P$-value $<0.05$ was considered statistically significant.

\section{Results}

Of the 92 physicians, 89 completed and returned the questionnaire (96\% response rate); 72 (80.9\%) respondents were male and $15(16.8 \%)$ were female (2 did not report their sex). The majority of physicians in the sample (50.6\%) reported having graduated from medical school before 1996.

\section{Preferred method of CME}

In the question about preferred methods of CME $69.7 \%$ of the respondents were very interested in medical conferences as a method for obtaining CME. The next most preferred methods

\begin{tabular}{ll}
\hline $\begin{array}{l}\text { Table } 1 \text { Locations of United Nations Relief and Works Agency for Palestine } \\
\text { Refugees in the Near East primary care clinics in Jordan }\end{array}$ \\
\hline Clinics within refugee camps & \multicolumn{1}{c}{ Clinics outside refugee camps } \\
\hline Amman new camp & Tybeh \\
Irbid & Aqaba \\
Jerash & Waggas \\
Husn & North Shoneh \\
Talbieh & Mashare \\
Suf & Kraymeh \\
Baqaa & Amman town health centre \\
South Baqaa & Zarqa town \\
Jabal Hussain & Amir Hasan Quarter \\
Zarqa camp & Awajan \\
Marka & Nuzha \\
Msheirfeh & \\
\hline
\end{tabular}




\begin{tabular}{|c|c|c|c|c|}
\hline \multirow[t]{2}{*}{ Method of accessing CME } & \multicolumn{2}{|c|}{ Very interested } & \multicolumn{2}{|c|}{ Somewhat/not interested } \\
\hline & No. & $\%$ & No. & $\%$ \\
\hline Medical conferences & 62 & 69.7 & 27 & 30.3 \\
\hline Brief courses & 58 & 65.2 & 31 & 34.8 \\
\hline Local lectures and case presentation & 52 & 58.4 & 37 & 41.6 \\
\hline Internet-based courses and modules & 47 & 52.8 & 42 & 47.2 \\
\hline Medical databases & 34 & 38.2 & 55 & 61.8 \\
\hline Webinars & 16 & 18.0 & 73 & 82.0 \\
\hline Medical journals & 0 & 0.0 & 89 & 100.0 \\
\hline Websites & 0 & 0.0 & 89 & 100.0 \\
\hline Other & 10 & 11.2 & 79 & 88.8 \\
\hline
\end{tabular}

were brief courses $(65.2 \%)$ and local lectures and case presentations (58.4\%). Although just over half of respondents $(52.8 \%)$ were interested in Internet modules, other modes of electronic delivery were less preferred (webinars 18.0\%, Internet databases $38.2 \%)$. None of the physicians reported an interest in accessing medical journals online or medical websites (Table 2).

\section{Current CME participation}

When asked about their current participation in CME $85.4 \%$ of physicians said they participated in medical lectures and $70.8 \%$ participated in brief courses. Participation in Internet-based CME was significantly lower, with $49.4 \%$ accessing CME through medical websites and only $31.5 \%$ using taking Internetbased courses and modules. One-fifth of respondents $(20.2 \%)$ reported accessing medical databases such as PubMed. Only 5.6\% participated in webinars (Table 3).

\section{Access to CME}

Although all UNRWA clinics in Jordan have an Internet connection, only $79.9 \%$ of the physicians surveyed reported that they had reliable access to the Internet, $37.0 \%$ reported having access to medical databases and 35.9\% had access to online medical journals.

\section{Paediatric topic preferences}

Physicians indicated that the paediatric topics they were most interested in were respiratory infections (76.4\%), followed by asthma (71.9\%), examination of the newborn (70.8\%), fever in infants $(70.8 \%)$, immunization updates $(70.8 \%)$ and gastrointestinal infections (69.7\%). Subjects that were of least interest included oral health (31.5\%), injury prevention $(42.7 \%)$ and behavioural problems (48.3\%) (Table 4).

\section{Preferences by year of graduation}

Further analysis of the data revealed that there was greater preference for online CME among those physicians who had graduated more recently from medical school: $91.3 \%$ among those who graduated between 2005 and 2012 versus $88.9 \%$ among those graduating before $1996(P=0.03)($ Table 5).

\begin{tabular}{lcccc}
\hline $\begin{array}{l}\text { Table } 3 \text { Current types of continuing medical education (CME) participation among physicians at United Nations Relief and } \\
\text { Works Agency clinics in Jordan }(\boldsymbol{n}=\mathbf{8 9})\end{array}$ & \multicolumn{3}{c}{ Participated } & \multicolumn{2}{c}{ Did not participate } \\
\hline Type of CME & No. & $\%$ & No. & \% \\
& 76 & 85.4 & 13 & 14.6 \\
Local lectures & 63 & 70.8 & 26 & 29.2 \\
Brief courses & 44 & 49.4 & 45 & 50.6 \\
Medical websites & 33 & 37.1 & 56 & 62.9 \\
Medical conferences & 28 & 31.5 & 60 & 67.4 \\
Internet based courses and modules & 27 & 30.3 & 62 & 69.7 \\
Medical journals & 18 & 20.2 & 71 & 79.8 \\
Medical databases & 5 & 5.6 & 84 & 94.4 \\
Webinars & 5 & 5.6 & 84 & 94.4 \\
Other & 88 & 98.9 & 1 & 1.1
\end{tabular}




\begin{tabular}{|c|c|c|c|c|}
\hline \multirow[t]{2}{*}{ Topic } & \multicolumn{2}{|c|}{ Very interested } & \multicolumn{2}{|c|}{ Somewhat/not interested } \\
\hline & No. & $\%$ & No. & $\%$ \\
\hline Respiratory infections & 68 & 76.4 & 21 & 23.6 \\
\hline Asthma & 64 & 71.9 & 25 & 28.1 \\
\hline Newborn examination & 63 & 70.8 & 26 & 29.2 \\
\hline Fever in small infant & 63 & 70.8 & 26 & 29.2 \\
\hline Immunization update & 63 & 70.8 & 26 & 29.2 \\
\hline Gastrointestinal infections & 62 & 69.7 & 27 & 30.3 \\
\hline Failure to thrive & 56 & 62.9 & 33 & 37.1 \\
\hline Micronutrient deficiencies & 55 & 61.8 & 34 & 38.2 \\
\hline Physician professional development & 55 & 61.8 & 34 & 38.2 \\
\hline Urinary tract infection & 53 & 59.6 & 36 & 40.4 \\
\hline Late preterm infants & 46 & 51.7 & 43 & 48.3 \\
\hline Behavioural and emotional problems & 43 & 48.3 & 46 & 51.7 \\
\hline Injury prevention & 38 & 42.7 & 51 & 57.3 \\
\hline Oral health & 28 & 31.5 & 61 & 68.5 \\
\hline Other & 5 & 5.6 & 84 & 94.4 \\
\hline
\end{tabular}

\section{Discussion}

Our data indicated that while most UNRWA physicians practising in Jordan reported that they had reliable access to the Internet, only $31.5 \%$ of the physician sample participated in Internet-based courses and modules, and similar numbers reported accessing online medical journals. The respondents reported a strong preference for live interactive courses and lectures when participating in CME. Although all UNRWA clinics in Jordan are connected to the Internet, $20.2 \%$ of the physicians reported that they did not have a reliable access to the Internet. This may be due to local issues or difficulties on the part of the physicians trying to access this resource.

In addition, the number of years since medical school graduation was significantly associated with lower interest in Internet-based CME delivery. Data from other regions regarding the relationship between physician age and Internet use for CME are scarce and conflicting (5-7). It is possible that among older physicians, less familiarity with computers and the Internet is a barrier to participation. Other possibilities might be that older physicians place a greater value on other aspects of group CME. These include the opportunity for a respite from practice or to experience personal interactions with teachers, colleagues and other professionals (8). Older physicians may also have a different understanding of the role played by the social environment in consolidating new knowledge (9). Research indicates that even in countries where Internet access is nearly universal, the traditional live CME format continues to be preferred by many physicians, although it is unclear whether physician's age is a factor in this preference $(10,11)$.

Paediatric topics reported to be of greatest interest included commonly seen paediatric conditions such as immunizations and asthma. Oral health, injury prevention and behavioural problems were of less interest. Previous

\begin{tabular}{|c|c|c|c|c|c|}
\hline \multirow[t]{3}{*}{ Graduation year } & \multicolumn{4}{|c|}{ Interest in Internet-based CME } & \multirow[t]{3}{*}{$P$-value } \\
\hline & \multicolumn{2}{|c|}{ Somewhat/not interested } & \multicolumn{2}{|c|}{ Very interested } & \\
\hline & No. & $\%$ & No. & $\%$ & \\
\hline 2005-2012 & 2 & 8.7 & 21 & 91.3 & 0.0316 \\
\hline 1997-2004 & 3 & 15.0 & 17 & 85.0 & \\
\hline 1996 and before & 5 & 11.1 & 40 & 88.9 & \\
\hline
\end{tabular}


research has suggested that physicians practising in the region may not have received much training in some of these topics (12). Additionally, they may consider some of these conditions to be outside of their sphere of responsibility (13). Therefore, CME on these important topics would be expected to improve the scope and quality of health care provided in these UNRWA primary care clinics.

Although the response rate to our survey was high, the questions on the survey did not explore preferences and barriers to physician CME preferences in depth. Further work should focus on detailing these barriers and assessing the effectiveness of different types of CME delivery on patient outcomes in the UNRWA setting.

A cost-effective health care system depends on a well-trained medical workforce. Continuing medical education is also an important means of coordinating and standardizing practices among a group of physicians across a medical system. These findings highlight the importance of understanding which specific types of CME activities are the most compelling to the target audience, and which are most likely to lead to measureable positive changes in clinical practice. Aligning modalities and subjects to take advantage of preferences, needs and resources available will allow the health organization to maximize cost-effectiveness of the CME provided, while allowing patients to benefit fully from new advances in medical care

\section{Funding: None.}

Competing interests: None declared.

\section{References}

1. Marinopoulos SS, Dorman T, Ratanawongsa N, Wilson LM, Ashar BH, Magaziner JL, et al. Effectiveness of continuing medical education. Rockville (MD): US Department of Health and Human Services, Agency for Healthcare Research and Quality; 2007 (AHRQ Evidence Report/Technology Assessment, Number 149).

2. Forsetlund L, Bjørndal A, Rashidian A, Jamtvedt G, O'Brien $\mathrm{MA}$, Wolf $\mathrm{F}$, et al. Continuing education meetings and workshops: effects on professional practice and health care outcomes. Cochrane Database Syst Rev. 2009; (2):CD003030. PMID:19370580

3. Bocco R. UNRWA and the Palestinian refugees: a history within history. Refug Surv Q. 2009;28(2-3):229-52.

4. Canchihuaman FA, Garcia PJ, Gloyd SS, Holmes KK. An interactive internet-based continuing education course on sexually transmitted diseases for physicians and midwives in Peru. PLoS One. 2011;6(5):e19318. PMID:21573054

5. Schoen MJ, Tipton EF, Houston TK, Funkhouser E, Levine DA, Estrada CA, et al. Characteristics that predict physician participation in a Web-based CME activity: the MI-Plus study. J Contin Educ Health Prof. 2009 Fall;29(4):246-53. PMID:19998447

6. Casebeer L, Engler S, Bennett N, Irvine M, Sulkes D, DesLauriers $M$, et al. A controlled trial of the effectiveness of internet CME. BMC Med. 2008 Dec 4;6:37. PMID:19055789

7. Alghamdi KM. Professional use of the internet among Saudi Arabian dermatologists: a cross-sectional survey. BMC Dermatol. 2009;9:10. PMID:19835598
8. Wolf FM, Gruppen LD, van Voorhees C, Stross JK. Dimensions of motivation for continuing medical education of primary care physicians. Eval Health Prof. 1986 Sep 1;9(3):305-16.

9. Sandars J, Kokotailo P, Singh G. The importance of social and collaborative learning for online CME (OCME): directions for future development and research. Med Teach. 2012 Aug;34(8):649-52. PMID:22830322

10. Stancic N, Mullen PD, Prokhorov AV, Frankowski RF, McAlister AL. Continuing medical education: what delivery format do physicians prefer? J Contin Educ Health Prof. 2003 Summer;23(3):162-7. PMID:14528787

11. Vollmar HC, Rieger MA, Butzlaff ME, Ostermann T. General Practitioners' preferences and use of educational media: a German perspective. BMC Health Serv Res. 2009;9(1):31. PMID:19220905

12. Barss P, Grivna M, Al-Maskari F, Kershaw G. Strengthening public health medicine training for medical students: development and evaluation of a lifestyle curriculum. Med Teach. 2008;30(9-10):e196-218. PMID:19117217

13. Kronfol NM. Access and barriers to health care delivery in Arab countries: a review. East Mediterr Health J. 2012 Dec;18(12):1239-46. PMID:23301399 